\title{
7 Fazit
}

In den Kapiteln 3 „Die Quellen des Jalkut Schimoni Zwölfprophetenbuch“ und 4 „Die Bearbeitung der Quellen im Jalkut Schimoni Zwölfprophetenbuch“ konnte gezeigt werden, wie der Autor des Jalkut durch die Verwendung von Quellen der palästinischen und babylonischen Tradition einen fortlaufenden Bibelkommentar erstellte. Dass er darüber hinaus, alle 12 Bücher der „kleinen“ Propheten als eine Gesamtschrift begriff, konnte im Kapitel 5 zur Textkomposition des Jalkut zum Zwölfprophetenbuch nachgewiesen werden: Der Autor des Jalkut entwickelt die Themen „Proselyten“ sowie „Messiaserwartung“ im Zuge seiner Gesamtkommentierung des Zwölfprophetenbuches. Er vertritt die Auffassung, dass das Prophetentum beendet ist, die Schechina aber weiterhin unter den Menschen in Israel weilt. Die Darstellung der Proselyten als hervorzuhebende Gruppe, ist zudem ein signifikantes Beispiel für ein Thema, das im Jalkut Schimoni eine konstant positive Bewertung erfährt. Dies verweist auf eine einheitliche Konzeption durch einen Autor oder eine Schultradition. Dasselbe gilt für die Thematisierung der „Völker der Welt“. Diese Gruppe tritt konsequent als Gegenspieler von Israel auf. Die eigene Arbeit des Autors im Zuge der Kommentarstrukturierung wird noch stärker in der Entwicklung von Themen deutlich. Die notwendige Quellenauswahl zu Gunsten einer solchen Textentwicklung steht in Diskrepanz zur Arbeit eines „klassischen“ Kompilators.

Als das wichtigste Forschungsergebnis dieser Arbeit ist zu benennen, dass erstmals über einen Textumfang von rund 240 hebräischen Seiten gezeigt werden konnte, wie der Autor die Quellen verwendet. Es wurde belegt, dass der Autor die Quellen verändert: Diese werden gekürzt, auseinandergeschnitten und in anderer Reihenfolge wieder zusammengesetzt, oft, indem weitere Textteile aus zweiten und dritten Quellen eingebaut werden. Der Autor des Jalkut ist damit weder Kompilator, noch Ersteller einer Anthologie, sondern ein Bibelkommentator, der die Bibel auf der Grundlage der rabbinischen Traditionsliteratur auslegt, aber mit seinen Quellen dabei frei umgeht und neue Akzente setzt, die in der Traditionsliteratur zuvor so nicht $\mathrm{zu}$ finden sind.

Mehr Informationen über den Kulturkreis, in dem der Jalkut Schimoni entstanden ist, könnten systematische Vergleiche mit den ähnlich aufgebauten Auslegungswerken Jalkut ha-Gadol und Lekach Tov bieten. ${ }^{1}$

1 Midrasch ha-Gadol aus dem Jemen, vgl. Günter Stemberger, Einleitung in Talmud und Midrasch (9. Aufl., München: C.H. Beck Verlag, 2011), 392-393; Lekach Tov wird Tobia ben Eliezer aus Mainz zugeordnet, später in Kastoria Griechenland, vgl. Günter Stemberger, Einleitung in Talmud und Midrasch (9. Aufl., München: C.H. Beck Verlag, 2011), 395. 
Auch wird es für eine genauere zeitliche Einordnung des Jalkut hilfreich sein, die textlichen Übereinstimmungen zwischen Raschi und dem Jalkut Schimoni textkritisch zu untersuchen. 